\title{
Young People's Response to The Response: The Impact of Political Diversity and Media Framing on Discussions of Combatant Tribunals ${ }^{1}$
}

\author{
Jeremy Stoddard \\ Associate Professor of Education \\ College of William \& Mary \\ jdstod@wm.edu \\ Jason Chen \\ Assistant Professor of Educational Psychology \\ College of William \& Mary \\ jachen@wm.edu
}

\begin{abstract}
This article presents results of a study of the impact of political dynamics on group deliberations of issues presented in the short film The Response. We selected four groups of 18-22 year-old participants based on political views, engagement, and efficacy (liberal, conservative, and two mixed groups), and asked them to view and discuss issues presented in The Response related to the combatant status review tribunals held at Guantanamo Bay. We found the groups with mixed political views had higher quality discussions of the issues and a better understanding of the issues post-discussion - in particular the tension between national security versus individual rights and of the nature of the tribunals. We also found a significant number of conservative group members became more conservative in their views as a result of their discussion. We discuss implications for secondary and post-secondary education as well as for political polarization overall in society.
\end{abstract}

\footnotetext{
${ }^{1}$ Funding for this study was provided by The Spencer Foundation under The New Civics strategic initiative. Special thanks to Diana Hess and Paula McAvoy, and to Katie McCall, Lauren Peterson, and Kim Hoer, graduate students at William \& Mary, for their help with this project.

Journal of Contemporary Issues in Education, 2016, 11(1), pp. 65-78

ISSN 1718-4770 @ 2016 University of Alberta/Centre for Global Citizenship Education and Research 


\section{Introduction and Relevant Literature}

One of the best ways to produce well-informed and active citizens is to engage students in structured deliberations of contemporary controversial issues (Hess, 2009; Parker, 2003). Some of the most impactful controversial issues from the past two decades have been associated with US domestic and foreign policies that resulted from the terrorist attacks on New York and Washington, DC on September 11, 2001. After the initial wave of international solidarity that followed these attacks, a vast array of controversial events and issues arose as a result of the "war on terror." These issues include actions taken by the US and other coalition military (e.g., Abu Graib, invasion of Iraq), and the role of domestic and international security agencies such as the NSA and CIA from the US conducting surveillance of electronic and other communications.

However, we know that these types of controversial issue deliberations are likely not occurring in schools (McAvoy \& Hess, 2013; Hess, 2009), and especially not around contemporary issues involving the war on terror or issues of privacy and national security being debated in the US. There is little evidence, for example, that US students are engaging in controversial issues related to the 9/11 terrorist attacks (Duckworth, 2015; Hess \& Stoddard, 2011; Stoddard, Hess, \& Hammer, 2011). Unfortunately, young people are also not likely engaging in multiple viewpoints on these issues viewed as controversial in society because of social and political stratification and the desire in schools to present events related to $9 / 11$ as a memorialization rather than engaging in controversial issues related to the US domestic and international response after $9 / 11$ (Duckworth, 2015).

\section{Political Talk and Media Engagement}

In general, people in the US are more likely to engage in political talk that reinforce their own views rather than challenge them because of social stratification, political polarization, and personalization of media sources and newsfeeds (Bishop, 2008; Pariser, 2011; Sunstein, 2007). This phenomenon has only grown as individuals, and young people in particular, are able to control their news stream via social media such as Twitter, and as a result of living and going to school with people who likely share their same views (Bishop, 2008; Pariser, 2011). In particular, how do young adults perceive the events of 9/11 and the war on terror, including the issues that have arisen as responses to these events, as they have largely grown up during a period of war where a rhetoric of fear of additional terrorist attacks and an emphasis on national security over civil liberties dominates the national media?

Promoting thoughtful discussions of media representations with political messages are further hampered by the often-held beliefs that media are objective sources of information, in particular when the film or media aligns with one's own views (Hess, 2007; Stoddard, 2009, 2013). This leads to the potential for amplification or homogenization effects related to a mediated message that is reinforced through discussion instead of challenged, analyzed, or examined from different perspectives (Sunstein, 2009; Fishkin \& Luskin, 1999, 2005). The same kind of political polarization 
that is occurring in society, as described by Bishop (2008), is also impacting the K-12 and college classroom in terms of the political diversity of the student population and the ability or willingness of teachers to engage students in contemporary political issues (McAvoy \& Hess, 2013). Students may be facing the same void of "cross-cutting political talk" (Mutz, 2006), or the exposure to divergent political views and arguments, in school as they are in their communities and social circles.

\section{Study: Young People's Response to The Response}

In this study we focus on how young people engage in the deliberation of one of the most iconic and long-lasting post-9/11 controversial issues - the form and function of the Combatant Status Review Tribunals (CSRT) held in Guantanamo Bay, Cuba. The CRST were designed by the administration of then President George W. Bush to determine whether or not combatants picked up on the "battlefields" of Iraq, Afghanistan, and other sites of the war on terror were being held legally. In particular, we examine the impact that media portrayals and political backgrounds of the participants have on their discussion and understanding of the issue. The guiding question that we explore here is: How do young people's political beliefs, knowledge and experiences influence their reading and discussion of The Response (and the issues it represents)?

We studied how four groups of participants (liberal, conservative, and two mixed), ages 18-22, viewed and discussed The Response. This group of participants were in middle school when the events of 9/11 occurred. We were interested, then, to see how they engaged with these issues through the film The Response, given the impact of the national narratives around terrorism during their adolescent development and their own personal experiences, identities, and political views.

The Response (2008), a dramatic film based on CSRTs held at Guantanamo Bay, Cuba, was designed to engage audiences in issues surrounding these tribunals, including US cultural ignorance toward Islam, the use of torture, and the veracity of evidence used against "unlawful enemy combatants." Roughly $93 \%$ of detainees reviewed in these tribunals were classified as legally held combatants. Over 500 of these "administrative hearings," or tribunals, were held at Guantanamo from 2004-2009, at which point they were suspended by the Boumediene v. Bush US Supreme Court ruling (2008) ${ }^{2}$.

The Response is a courtroom drama genre short film that includes two scenes: 1) a dramatic recreation of an Enemy Combatant Status Review Tribunal written using transcripts from actual hearings, and 2) the ensuing deliberation between the three Judge Advocate General (JAG) officers in a separate conference room. The film focuses on the structure and rules guiding the hearings, the case itself and whether or not the detainee should be classified as an unlawful enemy combatant, and contextual issues such as cultural misunderstandings of the concept of jihad and the political context of the trials (the role of the US Supreme Court and recent rulings in particular). Two of the most

\footnotetext{
2 Statistics and information on the Combatant Status Review Tribunals can be found at http://www.defense.gov/news/combatant_Tribunals.html (United States Department of Defense). Journal of Contemporary Issues in Education, 2016, 11(1), pp. 65-78 ISSN 1718-4770 @ 2016 University of Alberta/Centre for Global Citizenship Education and Research http://ejournals.library.ualberta.ca/index.php/JCIE
} 
controversial issues with these tribunals was the lack of legal representation for detainees and the inability of either the military Judge Advocate Generals ruling in the tribunals nor the detainees to see much of the often-questionable evidence used to justify their capture and continued detention because it was deemed classified for national security purposes.

The film ends with one JAG strongly making the case that the detainee should be further detained and a second arguing he should be released; JAG number three, on his first tribunal assignment, is shown pondering the evidence as the film goes to black and ends. This leaves the audience to decide. The writer/producer Sig Libowitz's goal with the film was to present all sides of the issue in order to engage audience members in deliberations of the core issues presented in the film. He believes that part of the success of the film is that it is not clearly for one side or the other on these issues. He wanted audience members to ask themselves "What would you do if you were in the place of one of these three judges?” (personal communication, March 20, 2013).

It is important to note that although the producers of the film made a conscious decision to attempt to treat the issue at hand as a sort of fair and equal representation of competing points of view, just raising this as a controversial issue and making the film with a somewhat sympathetic character in the detainee (played by Yasef Mandvi of The Daily Show), would make many view the film as against the tribunals and for the detainees. However, as it is impossible to separate political, or in this case legal, views from the production of any work, but especially a film, it is obvious that the producers of The Response have worked very hard to create a story that will engage people in the debates and not simply tell them what they think the "right" answer is.

The study builds from Seixas's $(1993,1994)$ examination of young people's ability to recognize and analyze issues of morality and historical representation in film. The conceptual framework builds from the field of sociocultural psychology, Wertsch (1998) and Schweber (2006) in particular, as a way to analyze the role of collective memory, the use of ideological narratives, and the impact of social context and interactions on participants' sense-making of media and the messages they contain. This framework will be used to analyze how political ideologies, meaning group beliefs that affect decisionmaking and meaning-making (Apple, 2004), as well as personal experiences and group dynamics, impact participants' meaning-making and views of media. Further, we examine the effects of how the film frames the issues and consequently how the groups frame the issues within their discussions, and in particular how the way that the issue is framed may shift the group dynamics and impact the direction and nature of the discussions and resulting meaning-making (Scheufele \& Tewksberry, 2007). Framing here connotes the belief that "how an issue is characterized [in media] can have an influence on how it is understood by audiences" (p. 11).

\section{Methods and Analysis}

\section{Participants}

Participants for the study included four groups of $18-22$ year olds ( $\mathrm{n}=30$ total). We selected this age group as: 1) it is rarely studied, 2) this group experienced 9/11 and the Journal of Contemporary Issues in Education, 2016, 11(1), pp. 65-78 ISSN 1718-4770 (C) 2016 University of Alberta/Centre for Global Citizenship Education and Research 
aftermath during their adolescent period, and 3) this group has been targeted in particular during the past five years by all political parties using social media and other new media. An initial online survey, developed from previously validated instruments, was used to create a pool of potential participants from the local region $(n=112)$.

From this pool of 112 potential participants who completed the survey, four groups of roughly eight to ten participants were selected with particular political make-ups: Group 1) liberal ( $\mathrm{n}=4,3$ males, 1 female), Group 2$)$ mixed strong views $(\mathrm{n}=11,8$ males, 3 females), Group 3) mixed moderate views ( $n=7,5$ males, 2 females), and Group 4) conservative ( $\mathrm{n}=8,3$ males, 5 females). Some of the groups were smaller than intended as a result of issues out of our control.

\section{Deliberations and Data Generation}

In addition to the online background survey, data used here include transcripts of the group discussions and data generated from items on questionnaires given prior to viewing the film (T1), immediately following the viewing (T2), and again after the discussion (T3). As part of the discussion participants were asked to discuss their interpretations of the film, the issues, ideas, and values, of the film, and to deliberate the issues raised in the film using evidence. The discussions lasted between 20-30 minutes and were guided by a "warm up" question, "In one or two words, how would you describe the film?," followed by opening with "If you were in the role of the JAG officer, would you find the detainee to be an enemy combatant?" and "are the tribunals fair?". These questions generated the bulk of the discussion naturally.

Below we present the major findings that illustrate the ways in which the participants "read" the issues in The Response based on their own views and how these views and interpretations impacted the discussions of the film. We then focus on implications in particular for K-12 and higher education in terms of the importance of engaging students in multiple perspectives of controversial issues and the importance of developing their students' abilities to engage in thoughtful discussion and deliberation.

\section{Findings}

Overall, the participants had powerful affective responses that led to rich discussions of the issues presented in The Response. Discussions varied in quality and impact on participants' views, however, based on the political makeup of the group and their own views and knowledge of the issues in the film. The discussions reflected the rhetoric of the debates over national security versus civil liberties that have dominated the US during the period of time when these participants moved from adolescence into early adulthood - and have very much shaped the collective memory and narrative templates (Wertsch, $1998,2004)$ through which they make sense of issues of terrorism and national security, even though they held differing ideological perspectives that lead them to different conclusions. 


\section{Political Diversity}

As other studies of this age group have found, there was little consistency in the participants' political views. Just because a participant was on the liberal end of our scale did not mean that they held these views on every issue. For example, the small liberal group was split two-to-two on whether or not the detainee should be classified as a combatant - which is the question the film leaves the audience with and one of the main questions the groups deliberated. Similarly, there were several in the conservative group who were unsure or were against the detainee being classified. This age group tends to exhibit more liberal views overall (Hess \& Ganzler, 2007), but this study includes a relatively small sample and there may have been bias based on the individuals that actually participated versus the larger group that was invited to participate in the study (for example, only four of the eleven that were invited and confirmed for one group completed the study).

Our survey to identify participant beliefs, however, also did not focus specifically on the issues in The Response in particular but on a number of contemporary political issues where there is strong disagreement across the political spectrum. The participants as a whole group were more conservative on four survey items related to issues of national security, terrorism, and foreign policy than on social or even economic issues, with the conservative group holding the highest mean score (2.34 on a scale of $1=$ liberal to $4=$ conservative). The moderate group had the lowest mean score at 1.91 (most liberal) while the two remaining groups were on the slightly conservative end with 2.16 . On the item asking whether or not the participants believed their civil liberties were being curbed as a result of the war on terror, all of the group means were on the disagree side, ranging from group mean scores of 2.36 on a scale of 4 at the low end to 3.0 at the high end. This more conservative view on issues of national security is likely due to the participants' generational experience in the post-9/11 era and war on terror, the rhetoric and atmosphere given their relative proximity to the Washington, DC area, as well as the group selection bias described above.

What is interesting to note here is that the mixed groups, which include those with conservative and liberal participants, had the vast majority of participants take the position that the detainee should "not" be classified, whereas two of the four liberal group participants took the position that he should be classified. Overall, those with less knowledge or without a clear position on the tribunals were more swayed, at least initially, after viewing the film on the post-viewing questionnaire. In the case of the conservative group, those participants with less knowledge of the issue were also swayed as a result of the discussion - a result of the group dynamics (discussed further below).

\section{Discussions of Issues in The Response}

There was evidence of "cross-cutting political talk" in all groups. The mixed strong group had more instances overall of divergent perspectives and a broader range of evidence drawn from the film. The liberal group was the smallest, the most civil, but also split on 
the issue of whether or not the detainee in the film should be classified as an enemy combatant, although all agreed the tribunals themselves were not fair.

Student 2: I would definitely have to say that he was an enemy combatant. Even if he was not, I just have to be safe. I would rather be safe than sorry to not mark him as an enemy combatant....

Student 3 (in response to Student 2): I guess I would have ruled that he was not based...I mean because there wasn't enough evidence and it didn't seem substantial. And I guess it's kind of like would you want to let a guilty person free or detain someone who you know might be innocent... I get the better safe than sorry, but then it's like but if he actually is innocent then I'd feel worse.

The evidence cited in this discussion was similar to that of the other discussions and drew heavily from the film: issues of evidence and being able to see evidence in the CSRT, issues around the bounties given for evidence or torture used to extract it, the inability of the detainees to have a lawyer, and the nature of the tribunals and length of detainment in particular before appearing before a tribunal. Here the students are engaging in the major universal issue in the film, and one that has been a constant during the post 9/11 era, the decision to favor national security over civil liberties even while recognizing a lack of fairness or justness in the process.

The size of the group and the strength of the participants' political engagement and efficacy led in part to Group 2 (mixed strong) having the most examples of cross-cutting talk and broadest level of participation. The discussion in this group went to a greater level of depth than Group 1 in exploring issues of morality related to human rights and the national security versus liberty debate. In particular, they build from a scene in the film where the JAG officers are debating the case they had just heard and emphasized notions of holding moral superiority as Americans.

Student 1:...I understand that we have to look for our own safety and soldiers, but this may sound cold, but the soldiers know what they're signing up for...The people who live in Iraq and Afghanistan, they don't have that luxury... We don't have a right to go in there and just take them prisoner because "oh, you might be a combatant." I completely understand what you're saying, but that doesn't mean it's right....I mean you still have to be moral.

Here the film and discussion have taken the students well beyond the initial issue of the detainee and into the role of the US in Afghanistan and the actions of soldiers as well as the US role oversees. Other students countered, however, with the national security defense by stating, for example, "but we still have to sleep at night..." Still others made the case that even given what has occurred, the US still maintained higher moral authority, noting "They're on a completely different scale" and "Their baseline is incalculably worse than even our lowest point." They argued that American soldiers on the ground were going to make the best decisions they could in regards to enemy combatants, while others argued that there were better alternatives to detainment at Journal of Contemporary Issues in Education, 2016, 11(1), pp. 65-78 ISSN 1718-4770 @ 2016 University of Alberta/Centre for Global Citizenship Education and Research http://ejournals.library.ualberta.ca/index.php/JCIE 
Guantanamo and about the nature of the tribunals, noting "If this man was an American citizen, he would have been acquitted."

\section{Ideological Framing and Persuasion/Manipulation in Discussions}

Although there were examples of cross-cutting political talk and the inclusion of multiple perspectives and evidence in each of the groups, there were also examples of framing and persuasion or even attempts at manipulation in two of the discussions. Framing refers to the ways in which a political advertisement or campaign attempts to position its potential audience to think about an issue in a certain way or "frame" the debate toward a particular goal (Scheufele \& Tewksbury, 2007). Similar to media framing, a discussion of an issue can also be framed to look at the issue from a perspective that may weigh the facilitators or particular group members' perspectives or ideological views more prominently than a "best case, fair hearing of competing points of view" (Kelly, 1986, p. 132) that is the standard for high quality controversial issues discussions (Hess, 2009).

In the case of the moderate mixed group, the discussion was framed by the emotional response below of one participant to the question regarding the detainee.

Is that even a question? How could you even consider answering yes to that on any sort of clean conscience or moral center, you know what I mean? It's a totally, $100 \%$, completely unjust, unethical, fascist institution where prisoners are guilty until proven innocent. Like I don't understand how anyone could operate within that with any semblance of moral conscience. (Group 3 participant)

This utterance quickly chilled the discussion and led to a less robust and diverse discussion. This was in part because this was the group that had lower levels of selfefficacy for political engagement, and in part because of the strong emotional reaction of the one participant above. In the case of this group, their perspectives came out more strongly in the questionnaire than in the discussion, as a number of members did not participate beyond a minimal level - especially if they disagreed with the above participant.

For those participants with little knowledge of the issues presented in the The Response, or those with already more liberal views, the film appeared to have an affective impact and sway them toward viewing the hearings as unfair. However, the participants were often swayed by others during the discussion or decided that the detainee should still be held even though they felt the hearings were unfair - the "better safe than sorry" reasoning identified above.

The strongest case of this occurred in Group 4, the conservative group. In this group, only three of the eight participants believed the detainee should continue to be held after viewing the film; however, after the discussion six agreed the detainee should be classified and held, with one as unsure and only one still against continued detention. These shifts in view appear to be a result of the very strong stances taken by some in the group about the detainee and hearings, which swayed many of those who were less sure.

Journal of Contemporary Issues in Education, 2016, 11(1), pp. 65-78 
One male participant in particular viewed himself as needing to maintain his conservative orthodoxy over engaging in thoughtful deliberation. He utilized commonly disputed statistics about Muslims and the war on terror to discredit the representation in the film and to attempt to persuade his fellow group to align their views with his own. For example, he argued that "...something like $70 \%$ of Pakistanis think it's ok to kill an American. So by that standard, you could take [any] one of them and they would be qualified to be put in Guantanamo" to make his case that even if there is doubt about the detainee, that he should still be held because of the risks.

He also made the assumption that the film, because it was "made by Hollywood" was therefore liberal. In response to another group member's reference to the film, he stated "I refuse to believe that's an accurate portrayal [the film]. That's made by a Hollywood director who I assume is defending terrorists in court...." which misrepresents both the film, which was not made in Hollywood, and the writer and producer, who practices white collar law and has not participated in any tribunals. Finally, in response to other participants' arguments centered around the rights of the detainee, and the need for a fair trial, he countered "I reject the idea that that's a constitutional argument...." This participant's arguments reflect not only a strong neo-conservative ideological view but also the narratives and talking points presented continuously by conservative news sources and politicians since the 9/11 attacks. Over the course of the discussion, these comments had an effect on the other group members, with the exception of one conservative group member who remained against holding the detainee because of her personal experience working with Muslim groups and her background in Middle Eastern Studies.

The effect of interjecting this evidence went beyond persuading other group members to shift their views on the detainee. It also affected their rationales for their decision from evidence from the film to evidence presented by the participant described above. For example, a Conservative Group member who was unsure at the beginning of the discussion about the detainee explained her shift in her position after the outspoken member of the conservative group presented the arguments above.

As I was writing [the questionnaire], I didn't actually think about any of that, but given that information, it's making me reflect back on some of these things. I do agree that they, he, does not deserve the same rights as the average American in a standard trial, but I do think the process that we have...does not seem like a systematic or helpful process...

Unlike the conservative group, where one member of the group in particular made it his job to attempt to persuade the group using information not included in the film and that has been refuted by other sources, the other groups saw little change in positions but more overall civil disagreement and discussion of the issues. In the mixed strong view group, where the discussion was more focused on the nature of the hearings as being unfair, the two participants who were "unsure" about the detainee prior to the discussion decided that he should not be held after the discussion. In the other two discussions, Journal of Contemporary Issues in Education, 2016, 11(1), pp. 65-78 ISSN 1718-4770 (C) 2016 University of Alberta/Centre for Global Citizenship Education and Research 
where the discussions were either more balanced and multiple perspectives on the issue were presented (liberal group) or not as open to competing perspectives (moderate), no one switched positions on the issue.

\section{Development of Knowledge on the Issue}

One of the most consistent effects seen in the data was that participants were able to provide more in-depth and nuanced evidence for their position and in their ability to identify political messages in the film after participating in the post viewing discussions, even when their own position did not change. For example, in response to a question about classifying the detainee as an unlawful enemy combatant that was asked on the T2 and T3 questionnaires, the responses below from a participant from the Mixed Strong group illustrates the shift in depth and nature of the warrant and evidence used even when the position of the participant does not change regarding whether the detainee should be classified. This participant responded "not sure" to the T1 questionnaire item asking for their understanding of what the objective of the CSRTs is prior to viewing The Response - meaning she was unsure of the purpose of the CSRTs. The following are this participant's T2 (post-viewing) and T3 (post-discussion) responses to the item asking whether they believed the detainee should be classified as an unlawful enemy combatant.

T2: No; they don't have sufficient evidence against him and the way that they attacked his beliefs was highly irrelevant and unnecessary and that cancels out any credibility that they had.

T3: No - it begs the question how far we are willing to go to take away someone's rights in order to potentially protect lives that we deem more valuable.

The T2 response reflects the more affective response to the film and how the tribunals are represented in The Response. His response in T3 reflects the discussion around human rights that emerged as part of the Mixed Strong Group discussion. They focused much more on the question of the fairness of the tribunal format and rules than on the portrayal of the detainee and potential threat he posed to national security. So, while this still reflects the larger narrative and rhetoric of national security versus civil liberties, this group of participants with strongly divergent political views was able to largely find consensus on this particular issue regarding the tribunals. This held true for those who maintained or switched their positions. Much of the evidence provided was from the film but utilized from the perspectives of the participants and their particular ideological views as part of the discussion when a participant warranted a statement.

\section{Implications}

This study illustrates the potential impact of political diversity on discussions of controversial issues related to the tension between national security and human rights. It also provides some insights into the impact of the post-9/11 national rhetoric in the United States on young people who were in middle school at the time of the attacks. This 
narrative of national security and the war on terror has been deeply engrained regardless of ideology.

One important finding is that even within largely homogeneous political groups there were participants with different views and positions on the issues in The Response. Similar to what McAvoy and Hess (2013) found in their study of controversial issues curriculum in schools, "even in classes that appear to be extremely homogeneous, students consistently reported that they were able to recognize and appreciate the ideological diversity in their midst if their teachers included discussions of controversial issues... [and] that the range of opinions expressed in their classes was far wider than in their homes..." (p. 40). This is important because schools, and society at large, have become more stratified by class, race, and political views over the past decade, thus limiting the exposure to competing perspectives on issues.

However, there are also important insights here for K-12 and college instructors who want to engage their students in discussions of controversial issues. The importance of having a safe environment for engaging in issues, and the need to have students learn norms for a deliberation of issues so as to not quell the speech of others was highlighted by the episode in the moderate group where the participant's strong reaction led to lower rates of participation and depth of discussion. Although this participant's reaction was an affective response to the power of the film, for most participants this immediate affectiveladen response in T2 became more reasoned, nuanced, and in-depth after the discussions (T3), which highlights the value of discussing and deliberating powerful issues presented in media.

There is also a lesson to be learned by the example of the conservative group, where young people with strong ideological views and the perspective that they need to persuade others of their views rather than exploring the issue using evidence from sources other than their selected source of information. It illustrates the kind of amplification of views that can occur within relatively like-minded groups where a strong ideological narrative is used to persuade others (Sunstein, 2009). It is also important to be aware of the role that particular narrative templates may be used to make sense of these issues (Wertsch, 2000). This emphasizes the need to help foster the information habits of young people through encouraging them to seek out multiple perspectives on events from multiple sources, to critique and analyze information sources, and to have an epistemic view of news sources as being constructed and holding particular perspectives regardless of their political views. It is important to have them reflect on or engage with potential counter or alternative narratives that may exist.

Finally, it is important to note the power of media to frame discussions of issues and present particular positions - or shift what the discussion is about. Overall the participants viewed the source as being a legitimate perspective on the events, in part no doubt because they were being shown it as part of a study on political views and media. However, they did not seem to really reflect on how the film had shaped their conversations and views on the issues presented in the film. This was particularly the case as many of the participants had little or no knowledge of the actual tribunals prior to Journal of Contemporary Issues in Education, 2016, 11(1), pp. 65-78 
viewing the film and were therefore more susceptible to the framing effect of the film. For teachers at all level, and those interested in developing a more active democratic citizenship in particular, this highlights the need to engage students young and old in the types of critical thinking necessary for them to weigh issues and evidence in order to be informed citizens who can take action to avoid extremist or ideologically-driven actions. Of course, this study also highlights the need for introspection on the parts of teachers to consider the films and texts they select to engage students in issues and how they frame those issues - and that they keep in mind the need to examining the "best case, fair hearing of competing views" Kelly (1986) advocates. 


\section{References}

Apple, M. (2004). Ideology and curriculum ( $3^{\text {rd }}$ edition). New York: Routledge Falmer.

Bishop, B. (2008). The big sort: Why the clustering of like-minded America is tearing us apart. Boston, MA: Houghton Mifflin.

Duckworth, C. (2015). 9/11 and collective memory in US classrooms: Teaching about terror. New York: Routledge.

Fishkin, J., \& Luskin, R. (1999). Bringing deliberation to the democratic dialogue: The NIC and beyond. In M. McCombs (Ed.), A poll with a human face: the national issues convention experiment in political communication (pp. 3-38). Mahwah, NJ: Lawrence Erlbaum.

Fishkin, J., \& Luskin, R. (2005). Experimenting with a democratic ideal: Deliberative polling and public opinion. Acta Politica, 40, 284-289. http://dx.doi.org/10.1057/palgrave.ap.5500121

Hess, D. (2007). From Banished to Brother Outsider, Miss Navajo to An Inconvenient Truth: Documentary films as perspective-laden narratives. Social Education, 71(4), 194-199.

Hess, D. (2009). Controversy in the classroom: The democratic power of discussion. New York, NY: Routledge.

Hess, D., \& Ganzler, L. (2007). Patriotism and ideological diversity in the classroom. In J. Westheimer (Ed). Pledging allegiance: The politics of patriotism in America's schools (pp 131-138). New York: Teachers College Press.

Hess, D., \& Stoddard, J. (2011). 9/11 in the curriculum: A retrospective. The Social Studies, 102, 75-79.

Kelly, T. E. (1986). Discussing controversial issues: Four perspectives on the teacher's

role. Theory and Research in Social Education, 19(2), 113-138. http://dx.doi.org/10.1080/00933104.1986.10505516

Libowitz, S. (Producer, Writer). (2008). The response. Look at the Moon Production.

McAvoy, P., \& Hess, D. (2013). Classroom deliberation in an era of political polarization. Curriculum Inquiry, 43(1), 14-47.

http://dx.doi.org/10.1111/curi.12000

Mutz, D. C. (2006). Hearing the other side: Deliberative versus participatory democracy. Cambridge University Press.

Pariser, E. (2011). The filter bubble: What the Internet is hiding from you. UK: Penguin.

Parker, W. (2003). Teaching democracy: Unity and diversity in public life. New York: Teachers College Press.

Scheufele, D. A., \& Tewksbury, D. (2007). Framing, agenda setting, and priming: The evolution of three media effects models. Journal of Communication, 57(1), 9-20.

Schweber, S. (2006). Fundamentally 9/11: The mechanics of collective memory in a fundamentalist Christian school. American Journal of Education, 112(3), 392417. http://dx.doi.org/10.1086/500714

Seixas, P. (1993). Popular film and young people's understanding of the history of Native American-White relations. The History Teacher, 26, 351-370. http://dx.doi.org/10.2307/494666

Seixas, P. (1994). Confronting the moral frames of popular film: Young people respond to historical revisionism. American Journal of Education, 102(3), 262- 285.

Journal of Contemporary Issues in Education, 2016, 11(1), pp. 65-78 
http://dx.doi.org/10.1086/444070

Stoddard, J. (2009). The ideological implications of using "educational" film to teach controversial events. Curriculum Inquiry, 39(3), 407-433. http://dx.doi.org/10.1111/j.1467-873X.2009.00450.x

Stoddard, J. (2013). Hilary: The Movie, The History Channel, and the challenge of the documentary for democratic education. Teachers College Record, 115(3), p. 1-32.

Stoddard, J., Hess, D., \& Hammer, C. (2011). The challenges of writing "first draft history": The evolution of the 9/11 attacks and their aftermath in school textbooks in the United States. In L. Yates, \& M. Grumet, M. (Eds.). 2011 World Yearbook of Education: Curriculum in today's world: Identities, politics, work, and knowledge, (pp. 223-236). New York: Routledge.

Sunstein, C. (2007). Republic.com 2.0. Princeton, NJ: Princeton University Press.

Sunstein, C. R. (2009). Going to extremes: How like minds unite and divide. Oxford University Press, USA.

Wertsch, J. V. (1998). Mind as action. New York, NY: Oxford University Press.

Wertsch, J. V. (2000). Narratives as cultural tools in sociocultural analysis: Official history in Soviet and post-Soviet Russia. Ethos, 28(4), 511-533. http://dx.doi.org/10.1525/eth.2000.28.4.511

Wertsch, J. (2004). Specific narratives and schematic narrative templates. In P. Seixas (Ed.) Theorizing Historical Consciousness (pp. 49-62). Toronto: University of Toronto Press. 